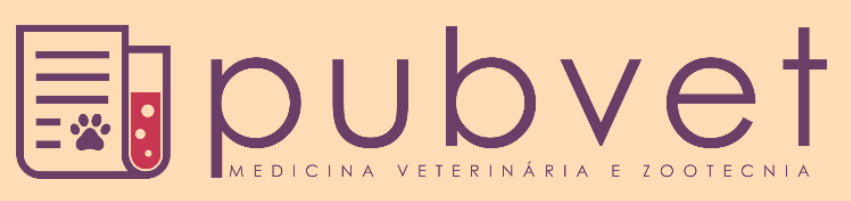

https://doi.org/10.31533/pubvet.v13n7a368.1-6

\title{
Presença de formas amastigotas de Leishmania sp em lesões de mamas inguinais em cadela
}

\author{
Jaqueline Anes de Souza ${ }^{1 *} \bullet$, Maristela Martins Halverson ${ }^{12} \bullet$, Henrique Jorge Vieira Antunes Junior ${ }^{10}$ \\ 1Programa de Aprimoramento em Medicina Veterinária da Universidade Anhanguera/Uniderp, Campo Grande- MS \\ 2Preceptora do Aprimoramento de Patologia Clínica do Curso de Medicina Veterinária Anhanguera Uniderp, Campo Grande - MS \\ *Autor para correspondência, E-mail: jaquelineanes.medvet@gmail.com
}

Resumo. A Leishmaniose é considerada de importância à saúde pública, onde a interação de diversos fatores atinge uma quantidade significativa de espécies. É uma doença crônica, que tem como vetor o mosquito Lutzomyia, inoculando o parasita Leishmania $s p$ nos hospedeiros quando no seu repasto sanguíneo, este dissemina-se rapidamente, aproveitando da imunossupressão e parasitando tecidos antes não relatados. Neste relato de caso será descrito o acometimento pelo parasita nos tecidos das lesões mamárias, em cadela de 4 anos, apresentando inchaço vulvar e lesões nas mamas inguinais. Foram realizados exames como hemograma e perfil bioquímico, complementando com citologias oncológicas dos locais das lesões. Algumas alterações foram observadas como anemia normocítica normocrômica, hiperproteinemia, e a presença concomitante do parasita Hepatozoon canis, tanto no esfregaço sanguíneo quanto no citológico. Já no esfregaço citológico, constatouse a compatibilidade com o Tumor Venéreo Transmissível Canino (TVTC) e na lesão mamária, um processo inflamatório, com pleomorfismo, atipias, grande quantidade de neutrófilos e macrófagos parasitados por formas amastigotas de Leishmania sp. O acometimento do parasita em tecidos ainda não relatados, mostra que o mesmo é oportunista, usam a imunossupressão para disseminar mais rapidamente, sendo necessário realizar uma pesquisa mais criteriosa das lesões presentes nos pacientes.

Palavras chave: amastigotas, citologia, inflamatório, tumor

\section{Presence of amastigote forms of Leishmania sp in lesions of inguinal breasts in a bitch}

Abstract Leishmaniasis is considered public health matter, where the interaction of several
factors affects a significant amount of species. It is a chronic disease, which has as vector
the Lutzomyia mosquito, inoculating the parasite Leishmania sp in the hosts when in its
blood supply, this disseminated rapidly, taking advantage of immunosuppression and
parasitizing previously unreported tissues. In this case report will be described the
involvement by the parasite in the tissues of the mammary lesions, in a dog of 4 years,
presenting vulvar swelling and lesions in the inguinal breasts. Tests were performed as a
hemogram and biochemical profile, complementing with oncological cytologies of lesion
sites. Some changes were observed as normocytic normochromic anemia,
hyperproteinemia, and the concomitant presence of the parasite Hepatozoon canis, both in
the blood and cytologic smear. In the cytologic smear, it was verified the compatibility with
the Canine Transmissible Venereal Canine tumor (TVTC) and the mammary lesion, an
inflammatory process, with pleomorphism, atypias, large amount of neutrophils and
macrophages parasitized by amastigotes forms of Leishmania sp. The involvement of the
parasite in tissues not yet reported, shows that it is opportunistic, use immunosuppression 
to spread more quickly, and a more careful investigation of the lesions present in the patients is necessary.

Keywords: amastigotes, cytology, inflammatory, tumor

\section{Presencia de formas amastigotes de Leishmania sp en lesiones de glándulas inguinales en perras}

Resumen. La leishmaniasis se considera de importancia para la salud pública, donde la interacción de varios factores afecta a una cantidad significativa de especies. Es una enfermedad crónica, que tiene como vector el mosquito Lutzomyia, que inocula el parásito Leishmania $s p$ en los hospedadores, este se disemina rápidamente en la sangre, aprovechando la inmunosupresión y parasitando tejidos no reportados previamente. En este caso se describirá la afectación del parásito en los tejidos de las lesiones mamarias, en una perra de 4 años, presentando hinchazón en la vulva y lesiones en las mamas inguinales. Se realizaron pruebas como hemograma y perfil bioquímico, complementando con la citología oncológica de los sitios de la lesión. Se observaron algunos cambios como anemia normocrómica normocítica, hiperproteinemia y la presencia concomitante del parásito Hepatozoon canis, tanto en la sangre como en el frotis citológico. En el frotis citológico, se verificó la compatibilidad con el tumor venéreo transmisible canino (TVTC) y en la lesión mamaria, un proceso inflamatorio, con pleomorfismo, atipia, una gran cantidad de neutrófilos y macrófagos parasitados por formas amastigotes de Leishmania sp. La participación del parásito en los tejidos aún no informados muestra que este es oportunista, usa la inmunosupresión para propagarse más rápidamente y es necesaria una investigación más cuidadosa de las lesiones presentes en los pacientes.

Palabras clave: amastigotes, citología, inflamatorio, tumor

\section{Introdução}

Considerada uma enfermidade de importância pública, a leishmaniose é uma doença que acomete cães, gatos, cavalos, roedores, humanos e mamíferos selvagens. Sendo observados diversos fatores, como ambientais, econômicos, populacionais, que podem influenciar na sua prevalência (Gontijo \& Carvalho, 2003; Gontijo \& Melo, 2004; Jesus \& Araújo, 2007). Uma doença crônica que acomete principalmente animais que foram picados pelo vetor Lutzomyia, quando este estiver parasitado pelo agente, inoculando o parasita na corrente sanguínea, o mesmo utiliza os macrófagos para sua divisão e multiplicação, disseminando-se pelo organismo, chegando a outros tecidos, alguns não relatados na literatura, porém susceptíveis ao parasitismo do protozoário Leishmania sp (Bowman, 2010). Estudos mostram que sua prevalência em animais jovens é significativa, sendo necessário confirmar em diagnósticos citológicos ou sorológicos, a presença ou a reação, respectivamente, do organismo frente ao parasita (Figueiredo et al., 2014).

O objetivo deste trabalho é relatar o caso de uma cadela de 4 anos, com lesões nas mamas inguinais e vulva. Foram realizados os exames hematológicos e citológicos, onde se constatou células neoplásicas compatíveis com Tumor Venéreo Transmissível Canino (TVTC) em vulva, e presença de células inflamatórias nas lesões mamárias inguinais, com a presença de formas amastigotas de Leishmania sp, parasitando macrófagos e de formas livres. As alterações laboratoriais se devem a presença da inflamação, a reação contra a neoplasia e ao acometimento pelo parasita, levando a alterações significativas relatadas posteriormente. Mediante o relato descrito, segundo Medeiros et al. (2008), os tumores mamários e de vulva se tornam locais susceptíveis ao acometimento pelo parasita.

\section{Materiais e métodos}

Foi atendida na Clínica Veterinária da Uniderp, uma cadela da raça Fox Paulistinha, quatro anos, com histórico de inchaço na vulva há 3 meses, após ter parido. O tutor relatou que a mesma aparentava dor e dificuldade de urinar. Segundo informações do mesmo, o animal era imunizado contra raiva, sua 
alimentação era composta de comida e ração, a casa possuía calçadas, e o animal compartilhava o quintal com mais um cachorro aparentemente saudável.

Os dados do exame clínico são Frequência Cardíaca (FC) de 160 bpm; Frequência Respiratória (FR) de $5 \mathrm{rpm}$; Temperatura retal de 39,0 C; Tempo de Preenchimento Capilar (TPC) igual a 3; mucosas hipocoradas, tanto ocular, quanto bucal; linfonodos pré-escapulares e poplíteos pouco aumentados. Foi observado também, conforme histórico do paciente, um nódulo vaginal consistente com abscesso lateral. Na glândula mamária, havia ondulação aparente, um nódulo consistente na mama inguinal direita e um nódulo macio na mama inguinal esquerda. A suspeita inicial relatada foi de TVTC. Foram realizados os exames complementares como, hemograma completo, bioquímicos séricos e citologia oncológica dos nódulos. Iniciou-se tratamento com anti-inflamatório, antibioticoterapia e suplementação alimentar até serem liberados os resultados dos exames.

No exame hematológico, verificou-se presença de anemia normocítica normocrômica, acompanhada de hemácias em Roleaux (+++) e com discretas anisocitose e policromasia. Hiperproteinemia, trombocitose, acompanhada de agregados plaquetários em grande quantidade e macroplaquetas também foram observados. Na pesquisa realizada no esfregaço sanguíneo foi visualizado somente o parasita intracelular Hepatozoon canis. O leucograma não apresentou alterações. Já nos exames bioquímicos, foram observadas; ureia diminuída, porém próxima da normalidade, alanina aminotransferase (ALT) diminuída, hipoalbuminemia e proteína total normal, porém perto do limite máximo.

No esfregaço citológico da lesão vulvar foi visualizado processo inflamatório bacteriano com células sugestivas de TVTC. Na lesão mamária, observou-se células epiteliais, com pleomorfismo, atipias, células inflamatórias representadas por muitos neutrófilos e macrófagos ativados, parasitados por formas amastigotas de Leishmania sp (Figura 1). De acordo com os protocolos da Clínica em casos de positividade para tal protozoário, a tutora foi orientada a procurar uma clínica particular de sua preferência para melhor adequar os tratamentos e providências quanto à saúde de seu animal.

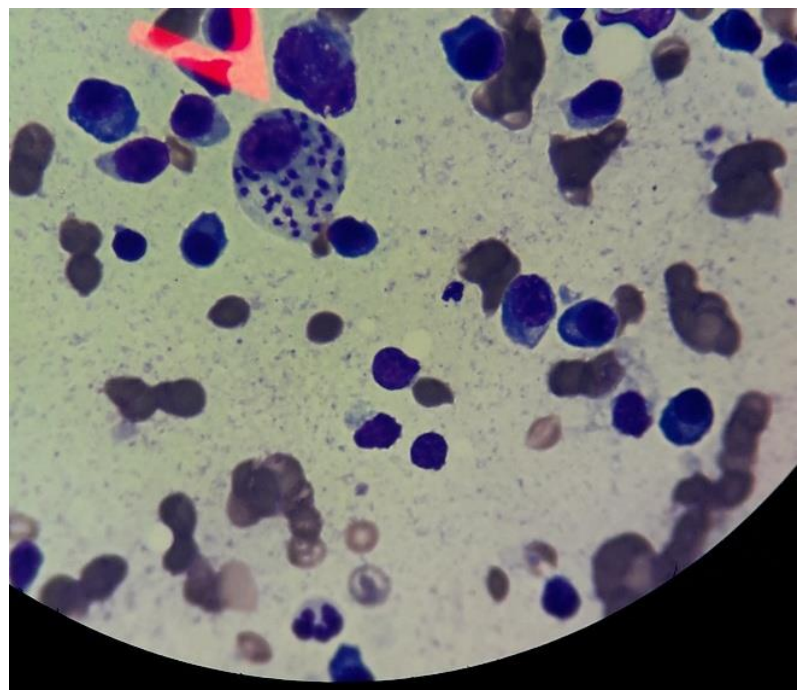

Figura 1: Macrófago parasitado por amastigotas de Leishmania sp (SETA) em citologia oncológica.

\section{Discussão}

Considerada uma enfermidade de importância a saúde pública, a Leishmaniose acomete principalmente os cães, mas pode acometer seres humanos, gatos, cavalos, roedores e mamíferos selvagens em outros continentes. Sua distribuição geográfica depende da movimentação populacional, disponibilidade de reservatórios, mudanças ambientais, assim como a baixa condição econômica (Gontijo \& Carvalho, 2003; Gontijo \& Melo, 2004; Jesus \& Araújo, 2007). É uma doença crônica, causada por um protozoário intracelular, a Leishmania sp, que habita macrófagos desses hospedeiros, sob forma de amastigotas, sendo denominada como Leishmania infantum chagasi, que é responsável pela leishmaniose visceral, ou calazar como também é chamada. A leishmaniose é disseminada pela picada do mosquito do gênero Lutzomyia, denominado assim no Novo Mundo (Bowman, 2010). 
Os mosquitos ingerem os macrófagos parasitados pelas amastigotas, então por divisão binária, por multiplicação, depois por diferenciação, assume a forma promastigota, este aderindo ao esôfago e à faringe do vetor. As formas diferenciadas de promastigotas metacíclicas são as formas infectantes, que serão disseminadas no hospedeiro quando for picado pelo vetor. Só então estas formas infectantes serão fagocitadas pelos macrófagos, e nestes serão diferenciadas em amastigotas por divisão binária também, rompendo estas células, são fagocitados por outros macrófagos e então a disseminação hematogênica e linfática ocorre, acometendo outros tecidos compostos por células mononucleares fagocitárias (Moreira et al., 2016; Schimming \& Silva, 2012).

Os cães podem ter sinais clínicos clássicos, como as úlceras cutâneas, alopecia,lesões de pele, principalmente dermatite esfoliativa, a onicogrifose, linfoadenopatia, hiperqueratose nasal e digital, podendo também ser assintomáticos, ou até mesmo apresentarem somente alguns dos sinais descritos. Portanto os diagnósticos laboratoriais são de importância significativa para exclusão de doenças com sinais clínicos semelhantes à leishmaniose (Desjeux, 2004; Moreira et al., 2016; Rodríguez-Cortés et al., 2010; Silva, 2007; Silva \& Braga, 2010).

Os estudos de prevalência de Leishmaniose Visceral Canina (LVC), em animais menores de 2 anos foram significativos, principalmente quando empregadas as técnicas de Ensaios Imunoenzimáticos (ELISA) e Reação de Imunofluorescência Indireta (RIFI), em lâminas fixadas com antígenos $L$. infantum, em cães sintomáticos, com maior acometimento de onicogrifose e alterações cutâneas (Figueiredo et al., 2014).

Os tumores mamários em fêmeas podem se desenvolver devido a fatores hormonais relacionados tanto ao estrógeno, quanto a prolactina, assim como, a progesterona em longo prazo, acarretando a proliferação dessas neoplasias (Daleck et al., 2016). O diagnóstico para configurar uma compatibilidade com neoplasia maligna, não depende somente de aspectos macroscópicos, mas sim do auxílio essencial da microscopia, sendo utilizada a técnica por punção aspirativa por agulha fina (P.A.A.F), onde são realizados os esfregaços para análise citológica e então visualiza-se aumentos excessivos de celularidade, quantidade de células mitóticas, características celulares compatíveis para cada tumor, como citoplasma, pleomorfismo nuclear, cromatina e evidência dos nucléolos (Diniz, 2007; Paranhos, 2014; Silva et al., 2014). Para o entendimento da relação entre o protozoário e a neoplasia, será descrito este relato de caso, relatando uma lesão em mamas inguinais, tanto direita quanto esquerda, parasitadas por amastigotas de Leishmania sp.

Diante das alterações macroscópicas das lesões mamárias observadas no animal, até mesmo do abscesso visualizado, de acordo com Medeiros et al. (2008), o hospedeiro pode tornar-se susceptível a enfermidades oportunistas mediadas por vetores devido ao seu estado de imunossupressão. Neste caso foi encontrado também Hepatozoon canis, transmitido pela ingestão do carrapato, tanto em esfregaço sanguíneo, quanto no exame citológico (Figura 2). Encontradas também as amastigotas de Leishmania $s p$, nos esfregaços citológicos das mamas inguinais.

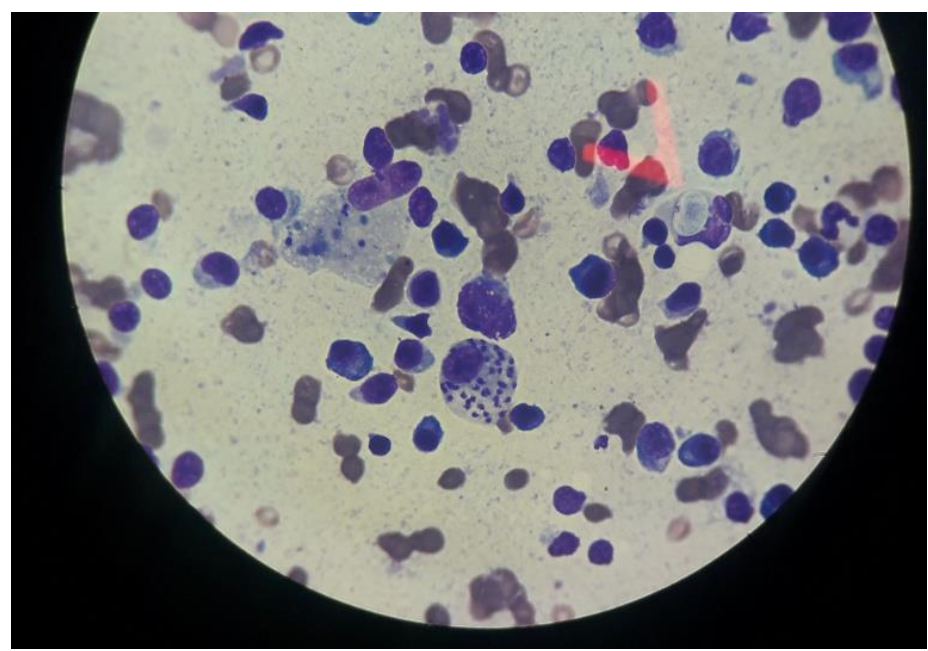

Figura 2. Neutrófilo parasitado por Hepatozoon canis em citologia oncológica (SETA). 
Para avaliação citológica, é necessário diferenciar o tumor mamário, tanto benigno quanto maligno, de lesões inflamatórias, sendo necessária uma avaliação histológica para verificar a malignidade dessa lesão (Cowell \& Tyler, 2009). A ocorrência de anemia normocítica normocrômica, além de outras enfermidades, pode acontecer devido ao acometimento por neoplasias. No caso relatado foi visualizada uma lesão em vulva, onde o diagnóstico citológico foi sugestivo para TVTC. Já a trombocitose pode ocorrer mediante doenças crônicas, na qual se encaixa a leishmaniose, essas alterações podem ocorrer também em casos de neoplasias, sem deixar de levar em consideração, os agregados plaquetários, que podem interferir na contagem das mesmas(Dias et al., 2015; Silva et al., 2004; Silva et al., 2014). A elevação das proteínas plasmáticas totais (PPT) tem sido observada na maioria dos casos positivos para LVC e pode ocorrer tanto pelo processo inflamatório causado pela mesma, bem como pela ativação dos linfócitos B e consequente elevação de anticorpos, preferencialmente gamaglobulina (Medeiros et al., 2008). Assim como a visualização de Roleaux no esfregaço sanguíneo, que pode evidenciar um aumento dos níveis séricos de globulinas (Weiss \& Wardrop, 2010). Durante a análise citológica, em esfregaço feito do conteúdo retirado da lesão das mamas inguinais, foram encontrados macrófagos parasitados por amastigotas de Leishmania sp. Este achado, não descrito anteriormente em nenhuma literatura, abre caminho para que novos estudos sobre o parasita Leishmania sp sejam realizados.

\section{Conclusão}

A ocorrência de achados de amastigotas de Leishmania sp. em lesões até então não relatadas, leva a uma preocupação dos profissionais em estudar mais casos de parasitismo por este protozoário, para que novos esclarecimentos sejam realizados. É necessário atentar-se ao analisar citologias oncológicas, à realização da pesquisa desses protozoários, que podem utilizar a imunossupressão do hospedeiro e as lesões presentes como uma oportunidade de proliferação.

\section{Referências bibliográficas}

Bowman, D. D. (2010). Parasitologia veterinária: Elsevier.

Cowell, R. L. \& Tyler, R. D. (2009). Diagnostic cytology and hematology of the horse E-Book. Amsterdam, Holanda: Elsevier Health Sciences.

Daleck, C. R., Fonseca, C. S. \& Canola, J. C. (2016). Oncologia em cães e gatos. Rio de Janeiro: Roca.

Desjeux, P. (2004). Leishmaniasis: current situation and new perspectives. Comparative immunology, microbiology and infectious diseases, 27(5):305-318.

Dias, F., Dias, L., Pereira, L., Cabrini, T. \& Rocha, J. (2015). Neoplasias orais nos animais de companhia-Revisão de literatura. Revista Científica Eletrônica de Medicina Veterinária, 20(1):1-9.

Diniz, S. d. A. (2007). Neoplasias intracranianas em cães: uma abordagem diagnóstica. Universidade de São Paulo, São Paulo.

Figueiredo, M. J. F. M., Souza, N. F., Figueiredo, H. F., Meneses, A. M. C., Silva Filho, E. \& Nascimento, G. G. (2014). Fatores de risco e classificação clínica associados à soropositividade para Leishmaniose Visceral Canina. Ciência Animal Brasileira, 15(1):102-106.

Gontijo, B. \& Carvalho, M. L. R. (2003). Leishmaniose tegumentar americana. Revista da Sociedade Brasileira de Medicina Tropical, 36(1):71-80.

Gontijo, C. M. F. \& Melo, M. N. (2004). Leishmaniose visceral no Brasil: quadro atual, desfios e perspectivas. Revista Brasileira de Epidemiologia, 7(3):338-349.

Jesus, J. R. \& Araújo, F. A. P. (2007). Leishmaniose tegumentar americana: uma visão da epidemiologia da doença na Região Sul. Clínica Veterinária, 12(71):82-84.

Medeiros, C. M. d. O., Melo, A. G. C., Lima, A. K. F., Silva, I. N. G. d., Oliveira, L. C. d. \& Silva, M. C. (2008). Perfil hematológico de cães com leishmaniose visceral nomunicípio de Fortaleza, Ceará. Ciência Animal, 18(1):43-50.

Moreira, N. B., Pinto, A. Z. L., Mutzemberg, E. R., Godoy, I., Silveira, M. M., Dutra, V. \& Sousa, R. F. (2016). Leishmaniose visceral canina: aspectos dermatológicos e dermatoses associadas. Acta Scientiae Veterinariae, 441-4. 
Paranhos, C. A. (2014). Neoplasias cutâneas caninas: um estudo descritivo de 4 anos. Master of Science, Universidade de Trás-os-Montes e Alto Douro, Vila Real.

Rodríguez-Cortés, A., Ojeda, A., Francino, O., López-Fuertes, L., Timón, M. \& Alberola, J. (2010). Leishmania infection: laboratory diagnosing in the absence of a "gold standard". The American Journal of Tropical Medicine and Hygiene, 82(2):251-256.

Schimming, B. C. \& Silva, J. R. C. P. (2012). Leishmaniose visceral canina - Revisão de literatura. Revista Científica Eletrônica de Medicina Veterinária, 10(18):1-5.

Silva, A. E., Serakides, R. \& Dantas Cassali, G. (2004). Carcinogênese hormonal e neoplasias hormôniodependentes. Ciência Rural, 34(2):625-633.

Silva, F. S. (2007). Patologia e patogênese da leishmaniose visceral canina. Revista Tropical-Ciencias Agrarias e Biologicas, 1(1):20-31.

Silva, O. A. \& Braga, G. M. S. (2010). Leishmaniose visceral canina no município de São Vicente Férrer, Estado de Pernambuco, Brasil. PUBVET, 4879-885.

Silva, P. D. G., Nardotto, J. R. B., Filgueiras, R. d. R. \& Mortari, A. C. (2014). Neoplasias intracranianas primárias em cães. Revista Científica de Medicina Veterinária, 12(40):11882-11882.

Weiss, D. J. \& Wardrop, J. K. (2010). Schalm's Veterinary Hematology. Iowa, USA.

Recebido: 28 de janeiro, 2019.

Aprovado: 28 de fevereiro, 2019.

Publicado: 30 de julho, 2019.

Licenciamento: Este artigo é publicado na modalidade Acesso Aberto sob a licença Creative Commons Atribuição 4.0 (CC-BY 4.0), a qual permite uso irrestrito, distribuição, reprodução em qualquer meio, desde que o autor e a fonte sejam devidamente creditados. 